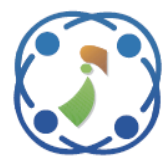

\title{
PSO-SMC Controller Based GMPPT Technique for Photovoltaic Panel Under Partial Shading Effect
}

\author{
Cheikhne Cheikh Ahmed $^{1 *} \quad$ Mohamed Cherkaoui $^{1} \quad$ Mohcine Mokhlis $^{1}$ \\ ${ }^{I}$ Department of Electrical Engineering, Mohammadia School of Engineers, \\ Mohammed V University in Rabat, Morocco \\ * Corresponding author's Email: Cheikhna03@yahoo.fr
}

\begin{abstract}
The effect of partial shading has a strong influence on the production of photovoltaic solar systems. In fact, when this phenomenon occurs, several power peaks appear on the power-voltage curve $(\mathrm{P}, \mathrm{V})$. These peaks are divided between the local maxima and a global maximum. This latter presents the superior maximum compared to the local maxima. Therefore, in this case, the conventional MPPT methods such as Incremental Conductance (INC) and Perturb and Observe $(\mathrm{P} \& \mathrm{O})$ do not have the ability to detect and track the highest peak. Thus, this causes the important loss of power. To overcome this issue, this study focusses on the design of a new method able to distinguish the global maximum power point (GMPP). This method is composed of two loops of control, the particle swarm optimization (PSO) and the sliding mode controller (SMC). The first loop, which consists of PSO, sweeps the power-voltage curve by looking for the GMPP, after that generates the reference of corresponding optimal voltage. While the second loop is designed to track the voltage reference by acting on the duty cycle of the SEPIC converter. This method is characterized by its robustness against the parameters' changes and the modeling error thanks to the SMC controller designed. In addition, the PSO used improves efficiency of the PV modules subjected to the non-uniform meteorological conditions. The simulation results show the rapidity and accuracy of the proposed method for localizing and tracking the global power maximum. In fact, according to the results, the proposed controller has a convergence time about $63 \mathrm{~ms}$ depending on the shading pattern. Moreover, it is able to detect the meteorological conditions change. To prove the advantages of the proposed technique, this one is compared with the hybrid controllers those composed of P\&O and INC combined with BSC and SMC controllers.
\end{abstract}

Keywords: Particle swarm optimization, Sliding mode control, Global MPPT technique, Photovoltaic module, Partial shading.

\section{Introduction}

It is no longer strategic today to rely on fossil fuels to produce energy because they are limited and have a negative impact on the environment. These characteristics have pushed countries to adopt new strategies on renewable and clean resources.

Among these sources, wind energy, hydropower and solar energy, the latter has grown very significantly because it has seen a rapid interest from world leaders in the field. Solar energy is one of the most widespread resources in the world due to its availability, simplicity and efficiency. It has the advantage of being able to install itself where it is needed without having many accessories. Effectively, that reduces the complexity compared to other renewable energy resources.

Solar energy is often used in two configurations, either to inject energy directly into the electricity grid or to supply isolated sites [1]. The production of solar energy is the subject of an influence of many factors, which are essentially the solar radiation and 
temperature. These factors are very random during the day. So, the PV system must be controlled in order to take these issues into consideration during the power production.

The tracking of the maximum power point techniques still under development. In fact, several techniques have been developed by scientists and researchers. Each controller designed is characterized by its specific yield, efficiency and implementation cost and complexity. Among these methods, there are the classical ones such as perturb and observe $(\mathrm{P} \& \mathrm{O})$ [2], incremental conductance (INC) [3] and hill climbing [4], these methods are simple and easiest to implement, but their great drawback is their fluctuations around the maximum power point which influences the accuracy and rapidity of the system [5]. In fact, in order to improve the tracking performances of the $\mathrm{P} \& \mathrm{O}$ and INC, these latter are combined with some nonlinear controllers (SMC, BSC) $[6,7]$ to obtain a hybrid method. In fact, in these studies, the $\mathrm{P} \& \mathrm{O}$ and INC are used to generate the reference of voltage instead on the duty cycle. So, in this case, the voltage is less influenced by the step variation than the duty cycle and they are more rapid and accurate than the classical methods.

This can be solved by using the artificial intelligence such as fuzzy logic [8] and artificial neural network $[9,10]$. These methods are efficient, accurate and capable of tracking the maximal power. However, they can distinguish the maximal point just under the uniform conditions of irradiation and temperature. Because, in this case, the power versus voltage presents only one maximal power peak. While under the partial shading conditions, where there are several points of maximal power, these methods cause high drop of energy, because they cannot distinguish the global maximum and tracks only the first maximum found at the right hand of the $\mathrm{P}-\mathrm{V}$ curve.

Solving these problems requires the use of the GMPPT technique such as the metaheuristic algorithms. In fact, the PSO [11-13], Genetic algorithm [14, 15], Cucko search [16, 17] and Ant colony optimization [18], are the most used algorithms because they can solve the multi objective problems. This paper focuses on the improvement of the tracking performances of the most used method that is the PSO algorithm.

In this paper, the PSO is combined with the sliding mode control in order to obtain a robust hybrid controller that is characterized by its good tracking performances. Indeed, the proposed controller can track the global maximum power rapidly and accurately whenever the partial shading takes place.
On the one hand, PSO algorithm is used to generate a reference of voltage that corresponds to the global maximal power point. While the sliding mode controller is designed thanks to its many advantages like its robustness against the modeling errors, external perturbations, and error of sensor measurements. On the other hand, the hybrid controller is more rapid and accurate than the classical methods [19]. Moreover, this controller is compared with some existing hybrid controller which are $\mathrm{P} \& \mathrm{O}$ combined with BSC [6] and SMC, and INC combined with BSC [7] and INC combined with SMC.

This paper is organized as follows. The second section presents the modeling of the photovoltaic system, while the third section is dedicated to the presentation of the proposed controller. The sections 4 and 5 are devoted to the investigation of the simulation results and the conclusion, respectively.

\section{Proposed system}

The system proposed in this article is composed of three photovoltaic panels, a DC-DC Sepic converter and a resistive load. The photovoltaic modules used can produce $55 \mathrm{~W}$ under the standard environmental conditions (Irradiation of $1000 \mathrm{~W} / \mathrm{m}^{2}$ and temperature of $25^{\circ} \mathrm{C}$ ) while the Sepic converter can Buck and Boost the voltage and can minimize the currents oscillations. This converter is directly connected to the load of $120 \Omega$. The following subsections in detail the modeling of the proposed system.

\section{Nomenclature}

$y$ : The output to control

P-V: Power versus Voltage

P\&O: Perturb and Observe

BSC: Backstepping Control

SMC: Sliding Mode Control

INC: Incremental conductance

$V_{p v}, I_{p v}: \mathrm{PV}$ voltage and current

$\mathrm{R}_{\mathrm{p}}, \mathrm{R}_{\mathrm{s}}$ : Parallel and series resistors

PSO: Particle Swarm Optimization

$C_{2}$ : The SEPIC converter Capacitor

$L_{1}, L_{2}$ : The SEPIC converter inductors

GMPP: Global Maximum Power Point

MPPT: Maximum Power Point Tracking

GMPPT: Global Maximum Power Point Tracking

SEPIC: Single-Ended Primary-Inductor Converter

$C_{l}, C_{3}$ : Input and output capacitors of the SEPIC converter 
$N_{p}, N_{s}$ : Number of PV modules connected in parallel and series

$$
I_{p v}=N_{p} I_{p h}-N_{p} I_{o}\left[e^{\left(\frac{q V p v}{N_{s} N_{c e l l} A K T}\right)}-1\right]
$$

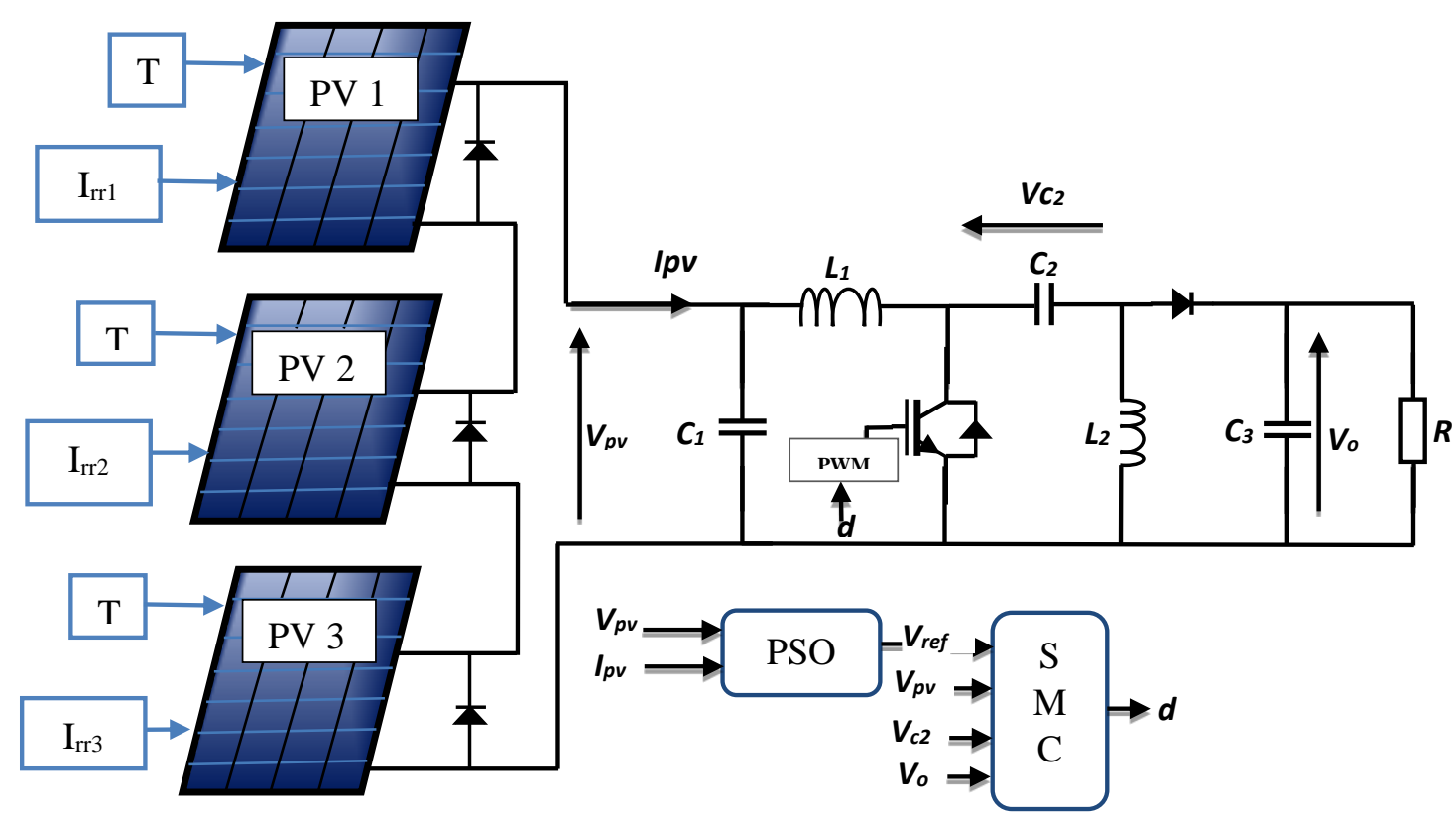

Figure. 1 Proposed system

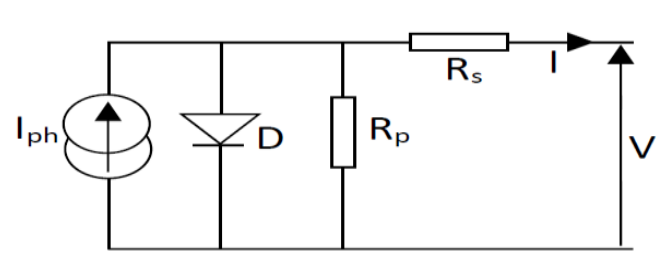

Figure. 2 PV cell

\subsection{Photovoltaic panel}

The solar panel is composed of a group of photovoltaic cells. These ones are manufactured on the basis of semiconductors that have the ability to transform the irradiation provided by the sun into electrical current.

Fig. 2 shows the standard model of a photovoltaic cell consisting of a current source, a single diode and two resistors (the parallel resistor $R_{p}$ and the series resistor $R_{s}$ ).

In fact, the series resistance $R_{S}$ is too small, while the parallel resistor $R_{p}$ so high. For this reason, to facilitate the control design of the sliding mode controller, which will be studied in the next section, these two resistors will be neglected. Because they do not have much influences on the control law measurement. Thus, neglecting these parameters helps to simplify the calculation without affecting accuracy [20].

The mathematical modeling of a photovoltaic panel can be expressed as follows:
Where:

$N_{\text {cell }}$ : The series cells number.

$A$ : The ideal factor of the PN junction. $q=1.6 \times 10 e^{19}[C]:$ The electron charge.

$V_{p v}[V]:$ The output voltage of the PV panel.

$I_{p v}[A]$ : The current of the photovoltaic panel.

$K=1.3805 \times 10 e^{23}[\mathrm{~J} / \mathrm{K}]$ : The Boltzmann constant.

Where,

$I_{p h}[A]$ is the photocurrent, it is given by the following formula:

$$
I_{p h}=\left[I_{s c r}+\left(K_{i}\left(T-T_{r}\right)\right)\right] \frac{E}{1000}
$$

With

$E\left[W / m^{2}\right]:$ The solar irradiation.

$K_{i}[A / K]$ : The temperature coefficient of the short circuit-current.

And,

The reverse saturation current $I_{o}$ is:

$$
I_{o}=I_{o r}\left(\frac{T}{T_{r}}\right)^{3} e^{\left(\frac{E g q}{K A}\left(\frac{1}{T_{r}}-\frac{1}{T}\right)\right)}
$$

With:

$E_{G}[\mathrm{eV}]$ : The bandgap's energy of the photovoltaic cell semiconductor is equal to $1.12 \mathrm{eV}$. 
$T_{r}[K]$ : The reference temperature of the cell that is equal $25^{\circ} \mathrm{C}$.

The reverse saturation current $I_{o r}$ measured at $T_{r}$ is:

$$
I_{o r}=\frac{I_{s c r}}{e^{\left(\frac{q V_{o c}}{K N_{S} A T}\right)}-1}
$$

With:

$V_{o c}[V]:$ the open circuit voltage.

$I_{s c r}[A]$ : the short-circuit current of the photovoltaic module measured under the standard irradiation $E_{r}$ and temperature $T_{r}$.

Using Equ. (1), the power of the photovoltaic module $P_{p v}$ can be obtained:

$$
P_{p v}=I_{p v} I_{p h} V_{p v}-N_{p} I_{o} V_{p v}\left[e^{\left(\frac{q V p v}{K N_{S} N_{c e l l} A T}\right)}\right.
$$

The characteristics of the photovoltaic module used are shown in the Table 1.

\subsection{Sepic converter modeling}

The Sepic converter is widely used for controlling power of PV panel under partial shading effect. In fact, On the one hand, the Buck converter cannot process the voltages' points close to the $I_{s c r}$, while the Boost converter cannot process the points of voltage close to the $V_{o c}$. On the other hand, As discussed before, unlike the Buck-Boost, the Sepic converter can provide the positive output voltage as well as a low ripple current at the input [21] - [22]. Moreover, the Sepic converter is able to function like Buck or BOOST according to the need act on the value of the duty cycle [21].

After analyzing the two states of the transistor switching, the following average model of the Sepic converter is obtained:

$$
\left\{\begin{array}{c}
\dot{V}_{p v}=\frac{1}{C_{1}} I_{p v}-\frac{1}{C_{1}} I_{L 1} \\
\dot{I}_{L 1}=\frac{1}{L_{1}} V_{p v}-\frac{1}{L_{1}}(1-d)\left(V_{C 2}+V_{o}\right) \\
\dot{V}_{C 2}=\frac{1}{C_{2}}(1-d) I_{L 1}+d \frac{1}{C_{2}} I_{L 2} \\
\dot{I}_{L 2}=d \frac{1}{L_{2}} V_{C 2}-(1-d) \frac{1}{L_{2}} V_{o} \\
\dot{V}_{o}=\frac{1}{C_{3}}\left(I_{L 1}+I_{L 2}\right)(1-d)-\frac{1}{C_{3} R} V_{o}
\end{array}\right.
$$

\section{Proposed method}

Under the uniform atmosphere conditions, the P$\mathrm{V}$ curve presents several peaks of power. The higher Table 1. PV module characteristics

\begin{tabular}{|c|c|}
\hline PV parameters & $\begin{array}{c}\text { Parameter } \\
\text { value }\end{array}$ \\
\hline Maximum power $\left(P_{\max }\right)$ & $55 \mathrm{~W}$ \\
\hline Optimal voltage $\left(V_{\text {opt }}\right)$ at $P_{\max }$ & $17.4 \mathrm{~V}$ \\
\hline $\begin{array}{c}\text { Maximum current Isc (short } \\
\text { circuit current) }\end{array}$ & $3.45 \mathrm{~A}$ \\
\hline $\begin{array}{c}\text { Maximum voltage } V_{o c}(\text { Open } \\
\text { circuit voltage) }\end{array}$ & $21.4 \mathrm{~V}$ \\
\hline Temperature coefficient $K_{i}$ & $1.4 \times 10^{-3} \mathrm{~A} /{ }^{\circ} \mathrm{C}$ \\
\hline Nomber of cell in series $N$ & 36 \\
\hline
\end{tabular}

one is widely called the global maximum. While the other peaks are called the local maximums.

The controller, shown in Fig. 1, is based on the PSO algorithm as well as the sliding mode controller. The PSO algorithm locates the global maximum power point by looking for the global peak and returns the output signal of the optimal voltage. In addition, the sliding mode controller (SMC) is designed in order to follow the reference voltage by acting on the Sepic converter's duty cycle. The main advantage of the proposed controller is to replace the conventional MPPT methods by overcoming their inability to follow the global maximum power point (GMPP) under the partial shading conditions.

\subsection{PSO MPPT}

The PSO algorithm is the optimization method that is widely used because it can solve the multiobjective problems. In this study, the objective function is the global maximum. Firstly, the PSO algorithm starts initializing the particles. Then, these particles converge iteratively to the optimal voltage that corresponds to the global maximum of power. Effectively, after any iteration, the particle, that corresponds to the superior power, still frozen in its position, while the other particles move by the position $\mathrm{x}_{\mathrm{i}}$. Finally, once the desired global maximum is reached, the corresponding optimal voltage is stored and returned as the output signal to follow. The particle convergence velocity is updated using the following equation:

$$
\begin{gathered}
v_{i}^{k+1}=w v_{i}^{k}+c_{1} r_{1}\left(p_{i_{\text {best }}}-x_{i}^{k}\right) \\
+c_{1} r_{1}\left(g_{\text {best }}-x_{i}^{k}\right)
\end{gathered}
$$

With:

W: The weight of inertia.

$c_{1}, c_{2}$ : The acceleration coefficients. 
$r_{1}, r_{2}$ : The random numbers those are limited between 0 and 1 .

The position $x$ is updated by the following equation:

$$
x_{i}^{k+1}=x_{i}^{k}+v_{i}^{k+1}
$$

In this study, the initial vector, composed of four particles $x^{1}=\left[V_{1}, V_{2}, V_{3}, V_{4}\right]$, is used.

When the condition Eq. (9) is satisfied, the search process, discussed previously, is stopped and the best solution among all the recorded solutions is defined as the optimal reference voltage to be followed by the power converter.

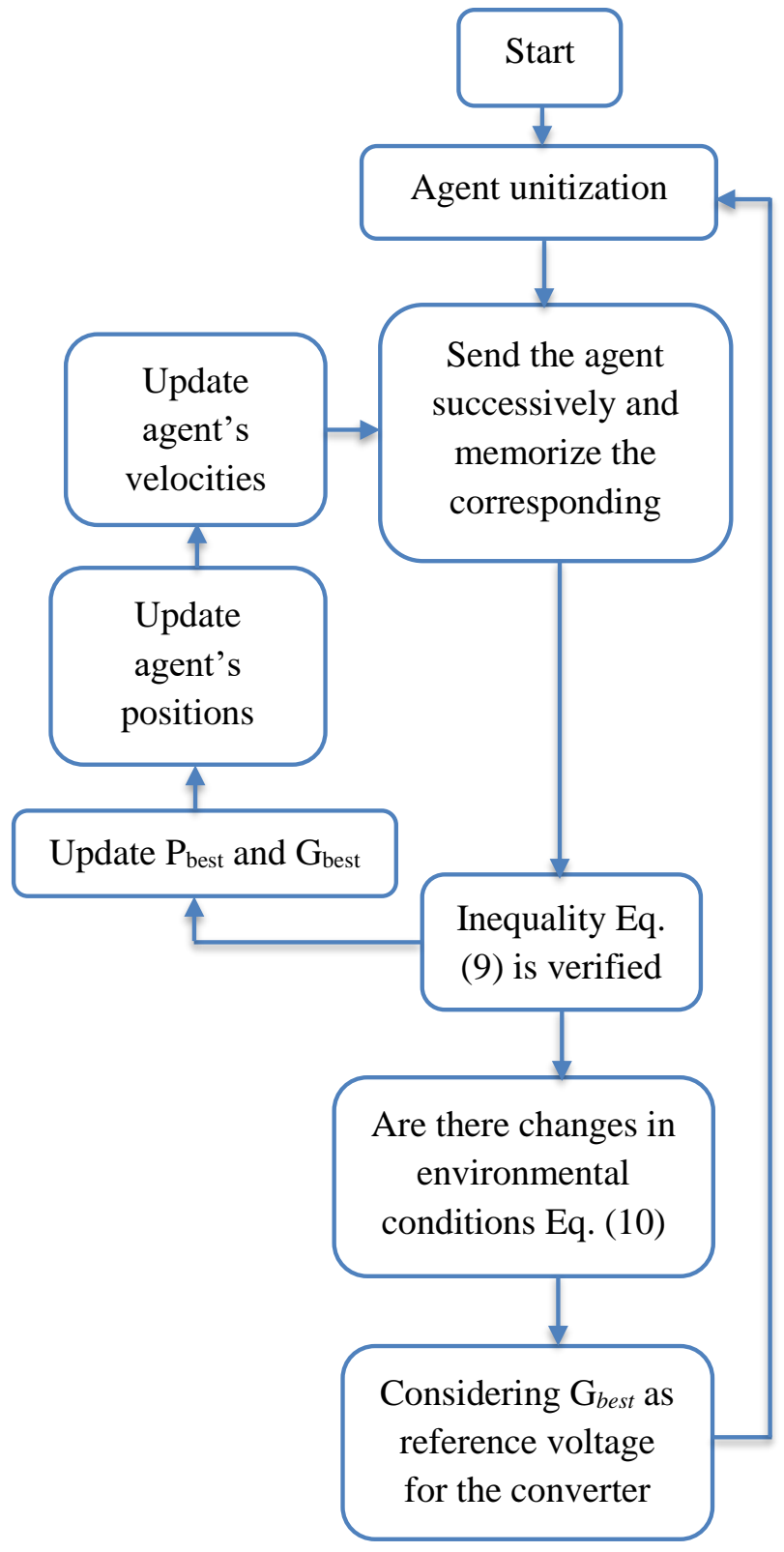

$$
\left\{\begin{array}{l}
P_{i}-P_{(i-1)} \leq 0.1 W \\
V_{i}-V_{(i-1)} \leq 0.05 V
\end{array}\right.
$$

It can be noted that any change of irradiation can influence the output power and the voltage as well. Therefore, to detect the meteorological conditions change, it should detects any variation of power and voltage, which can be verified when the condition (9) is satisfied. So, when the following condition is true, the controller restart the process of the new GMPP search:

$$
\left\{\begin{array}{l}
\left|\frac{P_{i}-P_{i-1}}{P_{i}}\right| \geq \Delta P_{\text {set }} \\
\left|V_{i}-V_{(i-1)}\right| \leq \Delta V_{\text {set }}
\end{array}\right.
$$

Where:

$\Delta P_{\text {set, }} \Delta V_{\text {set }}$ : the power and voltage thresholds, respectively. These ones are predetermined by the user.

(i), (i-1): The current and the previously measured values, respectively.

The sequential loop of this algorithm is illustrated in Fig. 3.

\subsection{Sliding mode control}

The sliding mode controller (SMC) is a nonlinear controller that is dedicated specially to the nonlinear systems. In this study, this controller is designed in order to track a reference of the optimal voltage by adjusting the SEPIC converter's duty cycle. During the SMC design, it should define the output $y$, which is in this case the PV voltage $V_{p v}$, and the output reference $y_{\text {ref }}$ which presents the optimal voltage reference $V_{r e f}$.

After that, it should follow the following steps: Firstly, define the sliding surface:

$$
s=\left(\lambda+\frac{d}{d t}\right) e^{r-1}
$$

with:

$e:$ The tracking error, it is equal $v_{p v}-v_{r e f}$.

$r$ : The relative degree $e$.

The derivative of output $y$ is:

$$
\dot{y}=\frac{1}{C_{1}} I_{p v}-\frac{1}{C_{1}} I_{L 1}
$$

Figure. 3 PSO-based MPPT controller Flow chart 
Thus, by using Equ. (6) and Equ. (12), the second derivative of $y$ can be expressed as follows:

$$
\begin{gathered}
\ddot{y}=\frac{1}{C_{1}} I_{p v}^{\prime}-\frac{1}{L_{1} C_{1}}\left[V_{p v}-(1-d)\left(V_{o}\right.\right. \\
\left.\left.+V_{C 2}\right)\right]
\end{gathered}
$$

As can be noted, the second derivation of $y$ makes appear the law control, which is the duty cycle of the SEPIC converter. Thus, the relative degree $r$ would be 2 . Therefore, the sliding surface will be:

$$
s=\left(\lambda+\frac{d}{d t}\right) e
$$

Consequently,

$$
s=\lambda e+\dot{e}
$$

The time derivative of the sliding surface $(s)$ is expressed as follows:

$$
\dot{s}=\lambda \dot{e}+\ddot{e}
$$

Where, the first time derivative of the tracking error $e$ is given by:

$$
\dot{e}=\dot{y}-\dot{y}_{r e f}=\dot{V}_{p v}-\dot{V}_{r e f}
$$

The second time derivative of $e$ can be expressed as follows:

$$
\ddot{e}=\ddot{y}-\ddot{y}_{r e f}=\ddot{V}_{p v}-\ddot{V}_{r e f}
$$

Replacing Equ. (13) in Equ. (18) the following expression is founded:

$$
\begin{aligned}
\ddot{e}= & \frac{1}{C_{1}} I_{p v}^{\prime}-\frac{1}{L_{1} C_{1}}\left[V_{p v}\right. \\
& \left.-(1-d)\left(V_{o}+V_{C 2}\right)\right] \\
& -\ddot{V}_{r e f}
\end{aligned}
$$

Therefore, considering $\dot{V}_{\text {ref }}$ and $\ddot{V}_{\text {ref }}$ equal to zero and replacing Equ. (17) and Equ. (19) in Equ. (16), the time derivative of the sliding mode surface will be:

$$
\begin{gathered}
\dot{s}=\lambda \dot{V}_{p v}+\frac{1}{C_{1}} I_{p v}^{\prime}-\frac{1}{L_{1} C_{1}}\left[V_{p v}-(1-\right. \\
\left.d)\left(V_{o}+V_{C 2}\right)\right]
\end{gathered}
$$

Knowing that, to ensure the stability, the first time derivative of $s$ should be:

$$
\dot{s}=-k \operatorname{signe}(s)
$$

So, by replacing Equ. (21) in Equ. (20), Equ. (22) can be obtained:

$$
\begin{gathered}
-k \operatorname{signe}(s)=\lambda \dot{V}_{p v}+\frac{1}{C_{1}} I_{p v}^{\prime}-\frac{1}{L_{1} C_{1}}\left[V_{p v}-\right. \\
\left.(1-d)\left(V_{o}+V_{C 2}\right)\right]
\end{gathered}
$$

Finally, the control law $d$ can be found as follows:

$$
\begin{gathered}
d=\frac{L_{1} C_{1}}{V_{o}+V_{C 2}}\left[\lambda \dot{V}_{p v}+\frac{1}{C_{1}} I_{p v}^{\prime}-\frac{1}{L_{1} C_{1}}\left[V_{p v}-\right.\right. \\
\left.\left.\left(V_{o}+V_{C 2}\right)\right]+\operatorname{ksigne}(s)\right]
\end{gathered}
$$

\section{Simulation result}

Three photovoltaic modules (Reference SM55) are connected in series and subjected to the different atmospheric conditions which can be uniform or nonuniform. The characteristics, of the PV modules used, are shown in Table 1.

As can be seen in Fig. 4, during the time interval $0 \mathrm{~s}$ and $2 \mathrm{~s}$, the sunshine conditions, applied to the photovoltaic modules, are considered uniform. While during the time interval $[2 \mathrm{~s}, 5 \mathrm{~s}]$, the PV modules are supposed under the partial shading effect. Effectively, under the partial shading effect, the Power-Voltage curve presents several maximum power points, as can be seen in Fig. 7.

The parameters of the proposed system components are as follows:

- $\quad$ The PSO parameters: $w=0.2, c_{1}=1.2, c_{2}=1.4$.

- SMC parameters: $K_{1}=470, K_{2}=230$.

- SEPIC parameters: $C_{l}=440 \mu f, L_{l}=0.35 \mathrm{mH}$, $C_{2}=440 \mu \mathrm{F}, L_{2}=0.35 \mathrm{mH}, C_{3}=470 \mu \mathrm{F}$, $R=120 \Omega$.

Fig. 5 shows the PV voltage at the PV panel terminals and the reference voltage as well. On the one hand, as depicts this figure, during any change of the irradiation and/or temperature, the PSO successively iterates until reaches the optimal voltage that corresponds to the global maximal power points.

In fact, that is made by considering four particles $\left(V_{1}, V_{2}, V_{3}\right.$ and $\left.V_{4}\right)$ which presents four different values of voltage. Then, the PSO algorithm starts measuring the power corresponding of each particle. After that, the four obtained powers will be compared, and the particle that corresponds to the maximal power rest frozen while the other particles move by step $v_{i}$ (convergence velocity) by using Eq. (6) and Eq. (7). This process repeats until all the four particles reach the global maximum power point. Indeed, that can be ensured when the condition shown in Eq. (8) is satisfied. Therefore, the particle (voltage) that corresponds to the global maximum power is 
memorized and returned as a reference of the optimal voltage. This latter is shown, in Fig. 5, in red color. All the process, discussed previously, starts again when the change of irradiation and/or temperature is detected. The detection condition is shown in Eq. (9).

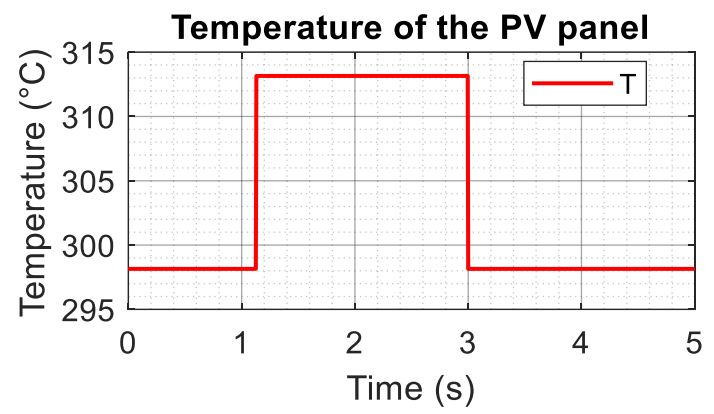

(a)

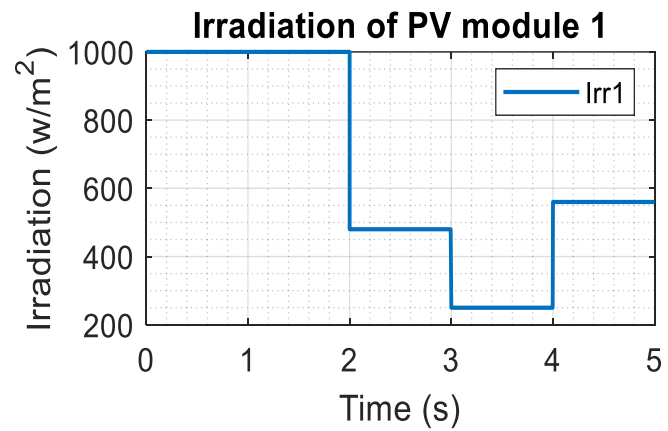

(b)

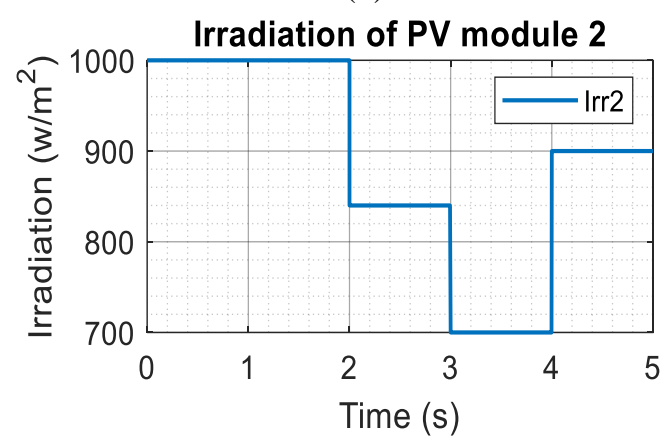

(c)

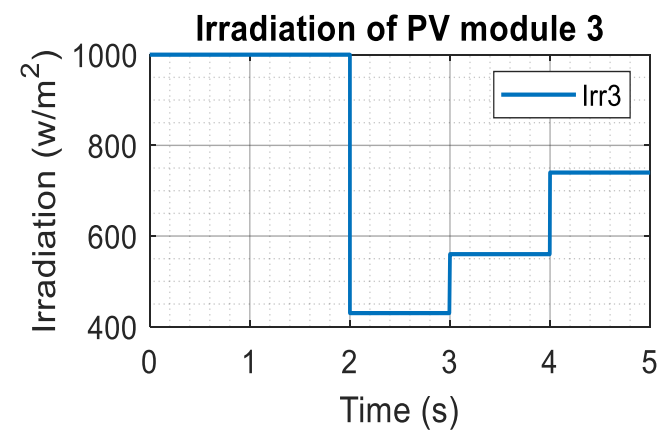

(d)

Figure. 4 Irradiations and temperature of the photovoltaic modules: (a) temperature of the PV panel, (b) irradiation of PV module 1, (c) irradiation of PV module 2, and (d) irradiation of PV module 3

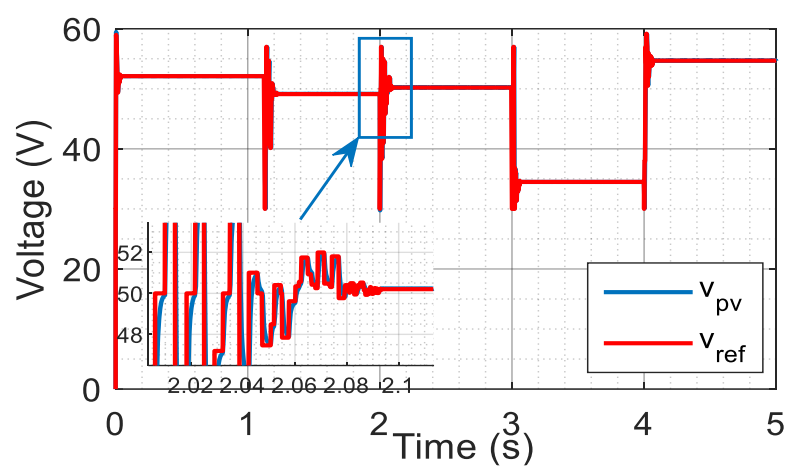

Figure. 5 PV panel voltage

While the PV voltage, that is shown in blue solid line curve, pursues rapidly and accurately this reference. Which proves the best criteria performances of the SMC controller designed.

In order to test and validate the proposed PSOSMC controller, this one is compared with the hybrid MPPT controllers, which are the P\&O and the INC algorithms combined with the Backstepping controller (BSC) and the sliding mode controller (SMC) as well.

On the one hand, as can be seen in Fig. 6, under the uniform conditions, both the proposed Global Maximum Power Point Tracking technique GMPPT and the hybrid MPPT techniques can track the maximum power point. Moreover, the proposed controller is more accurate and rapid than these controllers.

On the other hand, during the partial shading effect, the hybrid controllers can just track the global maximum very close to the $\mathrm{V}_{\mathrm{oc}}$, as can be noted in Fig. 7(a), Fig. 7(c) and Fig. 8. While when the GMPP is located at the middle in the P-V curve, as can be seen in Fig. 7(b), the hybrid MPPT controllers are not able to distinguish this point of the global maximum power, which proves the power drop between the time interval $[3 \mathrm{~s}, 4 \mathrm{~s}]$, see Fig. 6. However, the proposed GMPPT technique has succeeded to track the global maximum power point in this case, which proves the proposed controller ability to distinguish the desired maximum under the partial shading effect. Therefore, it can be concluded that the proposed controller has many advantages. Effectively, it can work properly under any meteorological condition, and obtains a system with good tracking performances. 


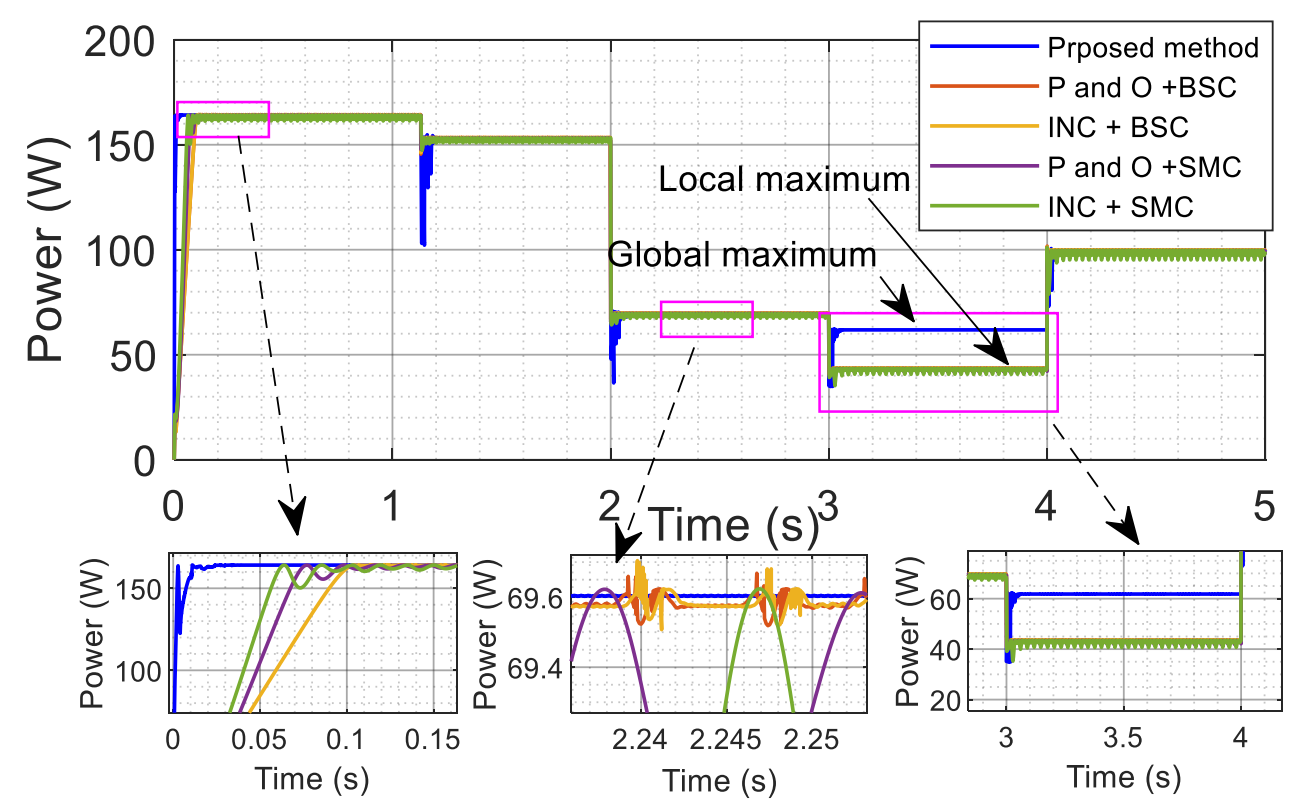

Figure. $6 \mathrm{PV}$ power at the terminals o PV panel by using the P\&O-SMC, P\&O-BSC, INC-SMC, INC-BSC and PSOSMC

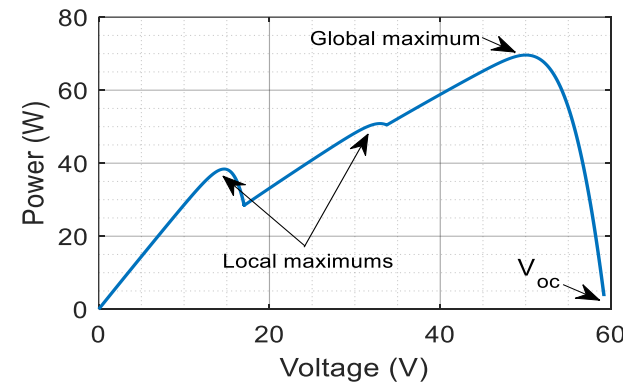

(a)

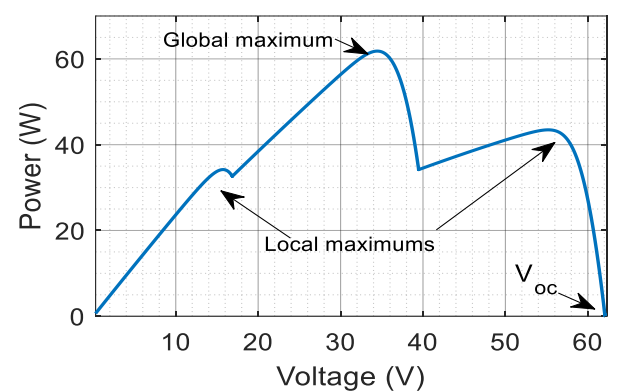

(b)

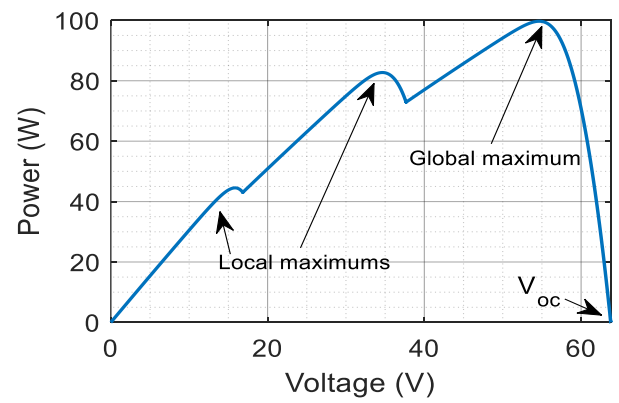

(c)

Figure. 7 Irradiations and temperature of the photovoltaic modules between the time intervals: (a) [2s, 3s], (b) [3s, $4 \mathrm{~s}]$, and (c) $[4 \mathrm{~s}, 5 \mathrm{~s}]$

\section{Conclusion}

In this study, an improvement of the PSO method is proposed. This method is combined with the sliding mode controller. On the one hand, the PSO controller sweeps the P-V curve and looks for the global maximum point of power. After that, generates the corresponding optimal voltage. While, the sliding mode controller is designed in order to track the reference generated. The sliding mode has shown its tracking performances of the reference voltage, while the PSO has proven its aptitude to find the GMPP under uniform and non-uniform meteorological conditions. Also, it localizes the GMPP rapidly about $63 \mathrm{~ms}$, which is the smaller convergence time compared to the classical methods. The results have shown the proposed controller can distinguish the GMPP while the P\&O-SMC, P\&O-BSC, INC-SMC and INC-BSC fail and cause considerable drop of power. Moreover, the proposed controller is more rapid and accurate than these methods. Thus, it can work properly under any atmospheric condition.

The future work will be concentrated on the implementation of the proposed controller on the external programmable board to validate its performances in the real time.

\section{References}

[1] M. Mokhlis and M. Ferfra, "Optimization of Photovoltaic Panels Efficiency Using a Backstepping Control Technique Under Partial Shading Conditions", International Review on 
Modelling and Simulations, Vol.10, No.36, pp.437-446, 2017.

[2] M. Abdel Salam, M. T. El Mohandes, and M. Goda, "An improved perturb-and-observe based MPPT method for PV systems under varying irradiation levels", Solar Energy, Vol.171, pp.547-561, 2018.

[3] M. Al Dhaifallah, A. M. Nassef, H. Rezk, and K. S. Nisar, "Optimal parameter design of fractional order control based INC-MPPT for PV system", Solar Energy, Vol.159, pp.650-664, 2018.

[4] H.-D. Liu, C. H. Lin, K. J. Pai, and Y. L. Lin, “A novel photovoltaic system control strategies for improving hill climbing algorithm efficiencies in consideration of radian and load effect", Energy Conversion and Management, Vol.165, pp. 815-826, 2018.

[5] M. Mokhlis, M. Ferfra, and M. Chraygane, "Nonlinear Control of a Photovoltaic Pumping System under Partial Shading”, In: Proc. of 2017 International Renewable and Sustainable Energy Conference (IRSEC), pp. 1-7, 2017.

[6] E. I. Rafika, A. Abbou, M. Mohcine, and M. Salimi, "A comparative study of MPPT controllers for photovoltaic pumping system", In: Proc. of the 9th International Renewable Energy Congress, pp.1-6, 2018.

[7] A. Taouni, A. Abbou, M. Akherraz, A. Ouchatti and R. Majdoul, "MPPT design for photovoltaic system using backstepping control with boost converter", In: Proc. of International Renewable and Sustainable Energy Conference, pp. 469475, 2016.

[8] M. Nabipour, M. Razaz, S. G. Seifossadat, and S. S. Mortazavi, "A new MPPT scheme based on a novel fuzzy approach", Renewable and Sustainable Energy Reviews, Vol.74, pp.11471169, 2017

[9] R. Kumar, H. P. Agrawal, A. Shah, and H. O. Bansal, "Maximum power point tracking in wind energy conversion system using radial basis function based neural network control strategy", Sustainable Energy Technologies and Assessments, Vol.36, p.100533, 2019.

[10] S. Issaadi, W. Issaadi, and A. Khireddine, "New intelligent control strategy by robust neural network algorithm for real time detection of an optimized maximum power tracking control in photovoltaic systems", Energy, Vol.187, p.115881, 2019

[11] M. Mao, L. Zhou, Z. Yang, Q. Zhang, C. Zheng, B. Xie, and Y. Wan, "A hybrid intelligent GMPPT algorithm for partial shading PV system", Control Engineering Practice, Vol.83, pp.108-115, 2019.

[12] M. Mao, L. Zhang, Q. Duan, and B. Chong, "Multilevel DC-link converter photovoltaic system with modified PSO based on maximum power point tracking”, Solar Energy, Vol.153, pp.329-342, 2017.

[13] H. Li, D. Yang, W. Su, J. Lu, and X. Yu, "An Overall Distribution Particle Swarm Optimization MPPT Algorithm for Photovoltaic System Under Partial Shading", IEEE Transactions on Industrial Electronics, Vol.66, No.1, pp.265-275, 2019.

[14] S. Hadji, J.-P. Gaubert, and F. Krim, "Real-Time Genetic Algorithms-Based MPPT: Study and Comparison (Theoretical an Experimental) with Conventional Methods", Energies, Vol.11, No.2, p. 459, 2018.

[15] Y. P. Huang, X. Chen, and C. E. Ye, "A Hybrid Maximum Power Point Tracking Approach for Photovoltaic Systems under Partial Shading Conditions Using a Modified Genetic Algorithm and the Firefly Algorithm", International Journal of Photoenergy, Vol.2018, pp. 1-13, 2018.

[16] A. F. Mirza, Q. Ling, M. Y. Javed, and M. Mansoor, "Novel MPPT techniques for photovoltaic systems under uniform irradiance and Partial shading", Solar Energy, Vol. 184, pp. 628-648, May 2019.

[17] D. A. Nugraha and K. L. Lian, "A Novel MPPT Method Based on Cuckoo Search Algorithm and Golden Section Search Algorithm for Partially Shaded PV System", Canadian Journal of Electrical and Computer Engineering, Vol. 42, No. 3, pp.173-182, 2019.

[18] S. K. Sahoo, M. Balamurugan, S. Anurag, R. Kumar, and V. Priya, "Maximum power point tracking for PV panels using ant colony optimization", In: Proc. of Innovations in Power and Advanced Computing Technologies, pp. 1-4, 2017.

[19] C. Cheikh Ahmed, M. Cherkaoui, and M. Mokhlis, "MPPT Control for Photovoltaic System using hybrid method under variant weather condition", In: Proc. of International Conference on Wireless Technologies, Embedded and Intelligent Systems, pp. 1-5, 2019.

[20] B. Lekshmi Sree and M. G. Umamaheswari, "A Hankel matrix reduced order SEPIC model for simplified voltage control optimization and MPPT”, Solar Energy, Vol.170, pp.280-292, 2018.

[21] M. Mokhlis, M. Ferfra, A. Abbou, and R. El idrissi, "Robust Control for Photovoltaic System 
Under Partial Shading Effect Using the SEPIC Converter", International Journal of Renewable Energy Research, Vol.9, No.2, pp.684-691, 2019.

[22] M. Luki Septya, I. Sudiharto, N. Syechu Dwitya, O. Asrarul Qudsi, and E. Sunarno, "Design And Implementation Soft-switching MPPT SEPIC Converter Using P\&O Algorithm", E3S Web of Conferences, Vol. 43, p.01010, 2018. 